REVI EWS

\title{
Teaching consistent hand hygiene: How can we improve?
}

\author{
Samantha K. Baggett ${ }^{1}$, Teresa Gore ${ }^{1}$, Bonnie K. Sanderson ${ }^{1}$, Chetan S. Sankar ${ }^{2}$ \\ 1. School of Nursing, Auburn University, Auburn, United States. 2. College of Business, Auburn University, Auburn, United \\ States.
}

Correspondence: Teresa Gore. Address: School of Nursing, Auburn University, 212 Miller Hall Auburn, United States. Email: goreter@auburn.edu

Received: September 6, 2013

DOI : $10.5430 /$ jnep.v4n1p200

Accepted: October 11, $2013 \quad$ Online Published: December 9, 2013

URL: http://dx.doi.org/10.5430/jnep.v4n1p200

\section{Abstract}

Background: Hand hygiene is the simplest, most effective measure for preventing nosocomial infections. However, this technique is not consistently translated into clinical practice. Educators must first evaluate current practices to determine what has been effective, what changes need to occur, how to evaluate, and what evidence provides guidelines for best practices.

Methods: This article examines current practices of instructing hand hygiene and describes teaching and evaluation strategies used in a nursing fundamental didactic and laboratory course. Instructors used educational strategies, lab practice, and mock hospital simulations to teach and evaluate hand hygiene compliance in the clinical setting. The authors used Kolb's Experiential Learning Theory during both lecture and lab to analyze the effectiveness of hand hygiene education and compliance during evaluations of undergraduate nursing students. Different simulation techniques were evaluated to determine implementations for future improvement.

Conclusion: Educators must continue to combine didactic courses and simulations labs to enhance the knowledge and improve skills of undergraduate nursing students. Educators must mentor each other and define clear objectives before teaching a lab simulation or lecture. More research is needed as to what specific concepts should be taught using learning and theoretical models that will ultimately improve patient safety through hand hygiene compliance when nurses go out into their practice settings.

\section{Key words}

Hand hygiene, Simulation, Undergraduate nursing student

\section{I ntroduction}

Hand hygiene is one of the first basic skills of patient safety taught to undergraduate nursing students. However, students may not carry this skill into clinical practice or further into their careers. Both student and healthcare providers' compliance to proper hand hygiene is unacceptably low ${ }^{[1,2]}$. Proper hand hygiene is emphasized as the single most effective way to reduce hospital acquired infections ${ }^{[2,3]}$. Millions of preventable deaths and billions of health care dollars could be saved if healthcare providers would carry this simple yet crucial skill into practice settings ${ }^{[4]}$. In the current 
environment of professional accountability, new graduate nurses must enter the clinical arena prepared to exhibit practices that maintain patient safety, which includes appropriate and consistent hand hygiene.

A variety of education strategies included within simulation has shown to increase hand hygiene compliance. Patient safety and quality of healthcare is directly correspondent to the competence of nurses and other healthcare professionals. National Council of State Boards of Nursing supports the use of simulations as a successful teaching experience ${ }^{[5]}$. It is vitally important for educators to continue evaluating these methods to improve hand hygiene technique ${ }^{[6]}$.

\section{Problem identification}

The question nurse educators must ask is "What is the best way to enable nursing students to consistently incorporate appropriate hand hygiene into their clinical practice?” The purposes of this article are to 1) provide a brief review of strategies used to improve hand hygiene practice in clinical settings and 2) describe teaching and evaluation strategies designed to improve hand hygiene practice in both the nursing school laboratory and clinical settings used in one southeastern baccalaureate school of nursing in Alabama.

\section{Review of literature}

Recent attention to hand hygiene as a patient safety issue has motivated extensive interventions and programming by national and international agencies such as the World Health Organization (WHO), Centers for Disease Control and Prevention (CDC) and The Joint Commission on Accreditation of Healthcare Organizations (JCAHO). Each organization provides detailed recommendations for proper hand hygiene ${ }^{[6,7,9,10]}$. Detailed education on recommended hand hygiene practices provided by these organizations must be emphasized early in preparing health professionals with the goal of transferring this priority into practice throughout their career ${ }^{[4,6,7,9,10]}$.

Around the world, simulation is being identified as an effective educational method that increases the competence of healthcare providers ${ }^{[11]}$. Nursing students have the ability to learn interactively and practice in a risk-free environment with immediate faculty feedback through simulation ${ }^{[12-18]}$. Useful tools and evaluations techniques have been identified to monitor and improve hand hygiene during simulation ${ }^{[19-24]}$. Direct observations with visual cueing such as using simulated germs and using questionnaires based on " 5 Moments for Hand Hygiene" are being used to evaluate and measure hand hygiene knowledge and compliance ${ }^{[6,7]}$. These hand hygiene simulations are being used in higher education and in healthcare facilities worldwide to improve patient outcomes overall. One benefit of simulation is repetitive practice using all the domains of learning (cognitive, affective, and psychomotor) for healthcare providers to ensure competency and learn using repetitive practices and visual cuing.

Theoretical models can greatly strengthen evidence to improve environments of patient safety ${ }^{[25]}$. Kolb’s Experiential Learning Theory (ELT) is applicable as it defines experiential learning as a process that is created through transforming the experience into application ${ }^{[26]}$. Patient care practice, as with any experiential learning concept, is not fixed. However, there are elements that can be formed and reformed throughout the experience. This may partly explain how information learned and practiced in the laboratory may not always transfer into clinical practice. For the information to be transferred into clinical practice, the student must have an initial experience to learn and then be allowed to reflect on the experience. In nursing schools, this is often incorporated within simulation where reflection is incorporated into the debriefing ${ }^{\text {[27] }}$. After reflection the student can conceptualize the practice and draw conclusions about the practice. This leads students to experiment or apply expected behaviours into the practice ${ }^{[28]}$.

\section{Theoretical application}

By applying Kolb's ELT, instructors may provide students the opportunity to perform skills in an initial clinical experience scenario and then reflect on their performance. During reflections, students are able to interpret the importance 
of concepts and apply those into their practice ${ }^{[29]}$. According to Kolb, experience leads to reflection, then to concepttualizing and then to action ${ }^{[26]}$. Action is a critically important part of the cycle. Experiential learning enhances scholastic learning by building confidence, encouraging risk taking, reducing the fear of failure, promoting collaboration, nurturing imagination and promoting problem solving ${ }^{[30]}$. Linking theory and practice will improve laboratory simulations and clinical scenarios ${ }^{[31,32]}$.

Simulation activities are prominent in this school of nursing and uses a conceptual framework based on the National League for Nursing (NLN)/Jefferies Simulation Model ${ }^{[33]}$, which was developed in nursing education to design, implement and evaluate simulation experiences. This model depicts the triadic relationship of students, faculty, and educational practices and their influence on the simulation design and desired outcomes. One of the simulation design characteristics is objectives/information along with the complexity of the simulation when designing the simulated clinical experience. Jeffries $(2005,2008)$ states that well written objectives are essential when designing an effective simulation scenario. The objectives should be comprehensive and provide the specific details required for the students to meet the outcome goal of the simulation experience. This framework is applicable to simulations because it allows faculty to focus on the objective of hand hygiene as one of the objectives in the experiential learning activity ${ }^{[33]}$. This allows faculty to use evidence-based practice to reinforce didactic information into the laboratory and clinical settings ${ }^{[34]}$. This conceptual framework also stresses the importance of a planned debriefing session, which the students can reflect on their practice in simulation.

\section{Teaching and evaluation strategies on hand hygiene}

The following describes teaching and evaluation strategies used on hand hygiene in a baccalaureate nursing degree program in a large land-grant southeastern university in Alabama. Demographics of the nursing student sample $(\mathrm{n}=51)$ included 92\% female students of which 96\% was Caucasian. The average age upon admission into the school of nursing their junior year was 21 years old. University Institutional Review Board (IRB) approval was granted for the use of the data during the simulation activities.

Patient safety concepts and skills are included in a fundamentals didactic, laboratory and clinical course. Patient safety teaching strategies included extensive didactic lectures and discussion with corresponding labs that included simulation activities. Faculty evaluated students through their performance in both quantitative assessment (e.g., written exam scores, including Health Education Systems, Inc. (HESI) standardized tests, self-report student surveys) and qualitative observations (e.g., simulation activities, anecdotal comments).

Didactic course. The didactic course is a four credit hour per semester class that practices a team teaching approach through various lectures and evaluations by faculty and graduate teaching assistants. Methods of evaluation within the course consist of the following: four unit examinations, two HESI final examinations, analysis of symptom papers and evidence based practice summaries.

The patient safety content focusing on hand hygiene occurs during lecture within the first three weeks of class and includes twenty PowerPoint ${ }^{\mathrm{TM}}$ slides dedicated to asepsis, infection and hand hygiene. The slides describe different types of asepsis and potential infections. Healthcare associated infections are highly emphasized during lecture followed by specific nursing steps to breaking the chain of these infections based on WHO Guidelines ${ }^{[23]}$.

Hand hygiene is stressed as the single most important thing healthcare workers could do to prevent infections. WHO's Guidelines including how-to picture charts on proper hand hygiene techniques and the " 5 Moments for Hand Hygiene" are depicted in the PowerPoint ${ }^{\mathrm{TM}}$. The picture charts gave detailed demonstration on how to properly wash hands or use alcohol rub. The "5 Moments for Hand Hygiene" defined by WHO include: before patient contact, before aseptic task, after patient contact, after body fluid exposure and after contact with patient surroundings. 
Clinical laboratory course. The concurrent three credit hour lab/clinical course focuses on skill practice and assessment using a team teaching approach by faculty and graduate teaching assistants. A total of 135 clinical hours provide practice and experience of concepts and theories learned. Practice and experiential learning activities are performed in the skills lab, clinical simulation scenario experiences, assessment and clinical lab experiences, and selected clinical sites in community agencies or acute care facilities. Weekly experiences provide students with demonstration of skills and various opportunities for practice to link didactic and application. Three skills and assessment validation check-offs are scheduled within the semester.

One clinical laboratory day is focused solely on personal safety. During this lab experience, students receive verbal and visual instructions and perform a return demonstration on personal protective equipment (PPE), surgical hand scrub, unsterile and sterile glove donning, and hand hygiene. The teaching technique of visual cueing is used when students apply GlitterBug ${ }^{T M}$ lotion to their hands and allowed it to dry. Once dry, students must wash and dry their hands using the techniques taught in class. Then students have their hands examined in a darkened room with a black light to evaluate the effectiveness of their hand hygiene. Students who do not perform the skill effectively receive instructions on how to improve their technique. That student must then repeat the hand hygiene process followed by black light evaluation.

Mock hospital unit simulation is a simulated clinical experience that provides first clinical semester students with the opportunity to practice patient care in a safe and controlled environment as their initial clinical experience. There is a specific focus on patient safety. Students work in groups of two to provide care for a simulated patient in a realistic hospital setting. The students have pre-simulation readings and questions. The students have a pre-briefing, simulation, and debriefing. Students were specifically questioned and guided on proper hand hygiene including hand sanitizer use and gloves during the simulation and in debriefing ${ }^{[35,36]}$.

Three skills validation and assessment check-offs are performed during the semester. Faculty developed skills validation checklist and students are given these checklist to practice prior to validation. Hand hygiene is incorporated into each skills validation. Course leaders observe students performing the skills and assessments.

In order to identify potential opportunities for improvement specific to patient safety and hand hygiene, a targeted review of student outcomes in both didactic and clinical laboratories was conducted.

\section{Results of evaluation of teaching strategies}

Didactic Course Evaluation. Hand hygiene test questions were incorporated into examination questions within the lecture course. Students were asked three specific questions related to hand hygiene. During test question analysis, faculty examined each individual question based on the percentage of class performance, the difficulty level of question as well as the biserial of each question. Each questions level of difficulty and biserial were in the educators' goal range. However, it was discovered that over $30 \%$ of students missed infection control and patient safety questions focusing on breaking chain of infection and standard precautions such as proper hand hygiene.

Hand hygiene and infection control questions are also included on the Fundamental and Assessment HESI examinations. While students achieved nationally benchmark scores overall on these comprehensive exams, there were lower than expected scores related to concepts of safety and infection control, safe/effective environment, basic safety design, culture of safety and safety monitoring as well as national patient safety resources.

Clinical Laboratory Evaluation. Despite the seemingly comprehensive approach to emphasize hand hygiene in both didactic and clinical lab exercises, students were not compliant $100 \%$ of the time with proper hand hygiene practice. After the mock hospital unit simulation, students were given surveys and asked to anonymously rate themselves on hand hygiene based on their performance during mock hospital (see Table 1). 
Table 1. Results of Self-Reported Hand Hygiene Compliance of 51 First Semester BSN Nursing Students

\begin{tabular}{|c|c|c|c|c|c|}
\hline Student self-reflection questionnaire. & $100 \%$ & $75 \%$ & $50 \%$ & $25 \%$ & $\mathbf{0 \%}$ \\
\hline $\begin{array}{l}\text { I washed my hands appropriately } \\
\text { in mock hospital BEFORE caring for the patient: }\end{array}$ & 30 & 13 & 5 & 2 & 1 \\
\hline $\begin{array}{l}\text { I washed my hands appropriately } \\
\text { in mock hospital AFTER caring for the patient: }\end{array}$ & 21 & 18 & 7 & 3 & 2 \\
\hline $\begin{array}{l}\text { I used gloves appropriately during } \\
\text { mock hospital (on for bathing, dressing/linen changes, etc.): }\end{array}$ & 16 & 18 & 15 & 0 & 2 \\
\hline $\begin{array}{l}\text { I kept my gloves on while charting } \\
\text { or when I was outside patients room: }\end{array}$ & 2 & 6 & 8 & 10 & 25 \\
\hline
\end{tabular}

Self-report student data reflected that students were using appropriate hand hygiene less than expected. In addition, faculty observed students not using of hand sanitizer prior to patient care and performing incorrect glove use during patient care. Students also occasionally wore contaminated gloves outside of the room and were not consistent in the use of hand sanitizer or hygiene hands after patient care. During these observations, faculty would intervene in the simulation and ask the student(s) to stop and reflect on the hand hygiene deficit. Some anecdotal responses students reflected a recurring theme: "I would have washed my hands and used gloves if it would have been a real patient." The faculty reminder was "you will perform the way you practice".

During skills validation, faculty members were allowing students to verbalize, "I would perform hand hygiene" before and after the skill. Faculty met after the mock hospital unit simulation to reflect on our current practices to identify gaps that may lead to lower student compliance of hand hygiene. Several areas were identified.

\section{Discussion: Future implications}

Past simulation evaluations have stopped at qualitative conclusions based on student self-report that the exercises provided beneficial learning experiences. However, based on both the qualitative and quantitative data gathered specific to hand hygiene, several opportunities for improvement were identified and are being implemented.

Visual Cueing. The GlitterBug ${ }^{T M}$ simulation used during the fourth clinical semester focusing on infection control and personal protective equipment uses visual cueing of contaminated surfaces in a patient's room on contact isolation precautions. This visual cueing was reported by students as a reminder of the importance of hand hygiene and made them more aware how easily they can spread infections to patients ${ }^{[37]}$. Because of its success rate and benefits to students, faculty will now use this simulation in first semester to show infection control and the importance of hand hygiene. This type of teaching technique will be incorporated for each semester until graduation instead of only once in a semester. Different types of visual cues can improve hand hygiene compliance ${ }^{[38]}$.

Visual cues will also be enhanced by posting laminated posters for hand hygiene from WHO in the laboratories for students to see on a daily basis. Consistent structured techniques must be performed throughout the nursing undergraduate's education for improvement compliance because of the declining compliance rates over time ${ }^{[1]}$.

Repeated behaviours performed by students within the appropriate environment with faculty facilitation are deliberate practice. Each task during simulation should be fully demonstrated and not just verbalized. In the past students have been allowed to verbalize "I would wash my hands now" but this will no longer be accepted as appropriate practice for simulation. For the three skills evaluation, hand hygiene is incorporated in the validation checklist prior to and after performing procedure due to the fact that the students are simulating the care they would provide to actual patients. Deliberate practice demonstrations will provide a visual picture of proper hand hygiene and form good habits for clinical scenarios ${ }^{[5,28]}$. 
Improved Access. During previous years, students had stated rationale for not using the hand sanitizers as inconvenience of sanitizer dispenser location. As a result of these comments, hand sanitizers are now affixed to the wall above the head of each bed in the laboratory, and made readily available on each bedside table and at the medication dispensing system.

Faculty Teamwork. Developing a well-rounded curriculum for faculty members to introduce to students is vitally important. Faculty must research collaboratively to determine the best methods and simulation specifications to be carried into the laboratory ${ }^{[39]}$. Adequate time should be allotted for faculty preparation to teach in simulations scenarios ${ }^{[8]}$. Every faculty member should know the objectives of the simulation prior to teaching undergraduates within the laboratory ${ }^{[40]}$. New faculty members to the simulation experience will meet with faculty members that are experienced in the simulation prior to participating in the simulation to identify specific objectives for simulation scenarios, including those focused specifically on patient safety and hand hygiene. Experienced faculty will act as mentors for faculty who have not taught that particular simulation. Faculty will use proper hand hygiene guidelines provided by the WHO ${ }^{[23]}$.

Direct Observation. Increased attention to direct observation of student hand hygiene practice during simulation will be emphasized in addition to self-report student surveys and reflections. Direct observation methods will help faculty evaluate first-hand how students value and perform patient safety through hand hygiene in the laboratory and clinical settings ${ }^{[41]}$.

\section{Conclusion}

Educators must evaluate current practices to help determine adherence to guidelines for best practice, identify opportunities for improvement, and implement measures to evaluate the effectiveness of practice changes. After going through this internal assessment process, educators can be more prepared to implement educational strategies for improved proper hand hygiene compliance ${ }^{[2]}$. Hand hygiene can be reinforced in all case scenarios. Educators must continue to combine didactic courses and simulations labs to enhance the knowledge and improve skills of undergraduate nursing students. Some healthcare programs and organizations are incorporating computerized devices and videos to collect hand hygiene compliance data. These finding will be useful for further research. If these technological advancements show improvement in patient safety skills such as hand hygiene, they could be used in simulations and continuing education methods for nursing and healthcare professional ${ }^{[42-45]}$.

More research is needed to define how to evaluate simulation effectiveness, support learning occurred and develop effective tools to measure if skills translated into the clinical and career paths ${ }^{[46]}$. Further studies are needed to determine whether this focus on hand hygiene within patient safety concepts can lead to a stronger foundation of the importance and proper technique of performing hand hygiene among emerging health care workers. More research is also needed to identify the most effective teaching strategies and concepts that integrate effective learning and theoretical models ${ }^{\text {[47-50] }}$. The ultimate goal is to improve patient safety, including adherence to hand hygiene principles that transfers from nursing school and continues when nurses go out into their practice settings.

\section{References}

[1] Gantt, L. T., \& Webb-Corbett, R. Using simulation to teach patient safety behaviors in undergraduate nursing education. The Journal of nursing education. 2010; 49(1): 48. PMid:19810666 http://dx.doi.org/10.3928/01484834-20090918-10

[2] Pittet, D. Improving Adherence to Hand Hygiene Practice: A Multidisciplinary Approach, Emerging Infectious Diseases. March-April 2001; 7(2). PMid:11294714 http://dx.doi.org/10.3201/eid0702.010217

[3] Gould, D., Chudleigh, J. H., Moralejo, D., \& Drey, N. Interventions to improve hand hygiene compliance in patient care. The Cochrane Library. 2009.

[4] Fitzpatrick, M., Everett-Thomas, R., Nevo, I., Shekher, I., Rosen, L.F., Scheinman, S.R., et al. A novel educational programme to improve knowledge regarding health care-asociated infection and hand hygiene. International Journal of Nursing Practice. 2011; 17: 269-274. PMid:21605267http://dx.doi.org/10.1111/j.1440-172X.2011.01934.x 
[5] Roche, J., Schoen, D., \& Kruzel, A. Human Patient Simulation Versus Written Case Studies for New Graduate Nurses in Nursing Orientation: A Pilot Study. Clinical Simulation in Nursing. 2012; 9(6): e199-e205. http://dx.doi.org/10.1016/j.ecns.2012.01.004

[6] Boyce, J. M. Hand hygiene compliance monitoring: current perspectives from the USA. Journal of Hospital Infection. 2008; 70: 2-7. http://dx.doi.org/10.1016/S0195-6701(08)60003-1

[7] The Joint Commission (TJC). Monograph: Measuring Hand Hygiene Adherence: Overcoming the challenges. Available from: http://www.jointcommission.org/Measuring_Hand_Hygiene_Adherence_Overcoming_the_Challenges_/ Retrieved September 5, 2013.

[8] The Joint Commission (TJC) Accreditation. Hospital National Patient Safety Goals. 2013. Available from: http://www.jointcommision.org

[9] World Health Organization (WHO). WHO Guidelines in Hand Hygiene in Health Care: A Summary. Geneva, Switzerland. Available from: http://www.who.int/gpsc/5may/tools/9789241597906/en/index.html

[10] Centers for Disease Control and Prevention CDCP): Guideline for hand hygyene in health-care settings: Recommendations of the Healthcare Infection Control Practices Advisory Committee and the HICPA/SHEA/APIC/IDSA Hand Hygiene Task Force. MMWR. Morbidity and Mortality Weekly Report 5 (RR-16),1-45

[11] Secomb, J., McKenna, L., \& Smith, C. The effectiveness of simulation activities on the cognitive abilities of undergraduate third-year nursing students: a randomised control trial. Journal of clinical nursing. 2012; 21(23-24): 3475-3484. PMid:23145517http://dx.doi.org/10.1111/j.1365-2702.2012.04257.x

[12] Feingold, C.E., Calaluce, M., \& Kallen, M. Computerized patient model and simulated clinical experiences: Evaluation with baccaureate nursing students. Journal of Nursing Education. 2004; 43: 154-163.

[13] Haskvitz, L.M., \& Koop, E.C. Students struggling in clinical? A new role for patient simulator. Journal of Nursing Education. 2004; 43: 181-184.

[14] McCausland, L.L., Curran, C.C., \& Cataldi, P. Use of human simulator for undergraduate nurse education. International Journal of Nursing Education Scholarship. 2004; 1(1): 1-17. PMid:16646889http://dx.doi.org/10.2202/1548-923X.1035

[15] Nehring, W., Ellis, W., \& Lashley, F. Human patient simulators in nursing education: An overview. Simulation \& Gaming. 2001; 32: 194-204. http://dx.doi.org/10.1177/104687810103200207

[16] Nehring, W., \& Lashley, F. Current use and opinions regarding human patient simulators in nursing education: An international survey. Nursing Education Perspectives. 2001; 25: 244-248. PMid:15508564

[17] Rauen, C.A. Simulation as a teaching strategy for nursing education and orientation in cardiac surgery. Critical Care Nurse. 2004; 24(3): 46-51. PMid:15206295

[18] Radhakrishnan, K., Roche, J. P., \& Cunningham, H. Measuring clinical practice parameters with human patient simulation: A pilot study. International Journal of Nursing Education Scholarship. 2007; 4(1). PMid:17402934 http://dx.doi.org/10.2202/1548-923X.1307

[19] Al Kadi, A., \& Salati, S. A. Hand hygiene practices among medical students. Interdisciplinary Perspectives on Infectious Diseases. 2012; Volume 2012. http://dx.doi.org/10.1155/2012/679129

[20] Aronson, B., Glynn, B., \& Squires, T. Competency assessment in simulated response to rescue events. Clinical Simulation in Nursing. 2012; 8(7): e289-e295. http://dx.doi.org/10.1016/j.ecns.2010.11.006

[21] Barsuk, J. H., Cohen, E. R., Feinglass, J., McGaghie, W. C., \& Wayne, D. B. Use of simulation-based education to reduce catheter-related bloodstream infections. Archives of internal medicine. 2009; 169(15): 1420. PMid:19667306 http://dx.doi.org/10.1001/archinternmed.2009.215

[22] Kreke, J. E., Schaefer, A. J., \& Roberts, M. S. Simulation and critical care modeling. Current opinion in critical care. 2004; 10(5): 395-398. PMid:15385758 http://dx.doi.org/10.1097/01.ccx.0000139361.30327.20

[23] Murphy, J.I. Using plan do study act to transform a simulation center. Clinical Simulation in Nursing. 2013; 9: e257-e264. International Nursing Association for Clinical Simulation and Learning, Elsevier Inc. http://dx.doi.org/10.1016/j.ecns.2012.03.002

[24] Phin, N. F., Rylands, A. J., Allan, J., Edwards, C., Enstone, J. E., \& Nguyen-Van-Tam, J. S. Personal protective equipment in an influenza pandemic: a UK simulation exercise. Journal of Hospital Infection. 2009; 71(1): 15-21. PMid:19013670 http://dx.doi.org/10.1016/j.jhin.2008.09.005

[25] Weaver, S. J., Lubomksi, L. H., Wilson, R. F., Pfoh, E. R., Martinez, K. A., \& Dy, S. M. Promoting a Culture of Safety as a Patient Safety StrategyA Systematic Review. Annals of internal medicine. 2013; 158(5_Part_2): 369-374. PMid:23460092 http://dx.doi.org/10.7326/0003-4819-158-5-201303051-00002

[26] Kolb, D. A. Experiential learning: Experience as the source of learning and development. Experiential Learning. PrenticeHall, Englewood Cliffs. 1984; 28-30.

[27] Cantrell, M. A. The importance of debriefing in clinical simulations. Clinical simulation in nursing. 2008; 4(2): e19-e23. http://dx.doi.org/10.1016/j.ecns.2008.06.006 
[28] Ford, P. D., \& Benito Velasquez, D. A. Dynamic paired-behaviors in effective clinical instruction. Instructor. 2010 ; 5: 10.

[29] Gore, T., \& Schuessler, J. B. Simulation Policy Development: Lessons Learned. Clinical Simulation in Nursing. 2012.

[30] McKenzie, M. Rescuing education: the rise of experiential learning. Independent School. 20136; 72(3): 24-28.

[31] Childs, J. C., \& Sepples, S. Clinical teaching by simulation lessons learned from a complex patient care scenario. Nursing Education Perspectives. 2006; 27(3): 154-158.

[32] Cioffi, J. Clinical simulations: development and validation. Nurse Education Today. 2001; 21(6): 477-486. PMid:11466011 http://dx.doi.org/10.1054/nedt.2001.0584

[33] Jeffries, P. R. A frame work for designing, implementing, and evaluating simulations used as teaching strategies in nursing. Nursing Education Perspectives. 2005; 26(2): 96-103. PMid:15921126

[34] Pope, W. S., Gore, T., \& Renfroe, K. C. Innovative teaching strategy for promoting academic integrity in simulation. Journal of Nursing Education and Practice. 2013; 3(7): 30. http://dx.doi.org/10.5430/jnep.v3n7p30

[35] Gore, T., Hunt, C. W., \& Raines, K. H. Mock hospital unit simulation: A teaching strategy to promote safe patient care. Clinical Simulation in Nursing. 2008; 4(3): e57-e64. http://dx.doi.org/10.1016/j.ecns.2008.08.006

[36] Gore, T., Hunt, C. W., Parker, F., \& Raines, K. H. The Effects of Simulated Clinical Experiences on Anxiety: Nursing Students' Perspectives. Clinical simulation in nursing. 2011; 7(5): e175-e180. http://dx.doi.org/10.1016/j.ecns.2010.02.001

[37] Mittal, M.K., Morris, J.B., Kelz, R.R. Germ simulation: a novel approach for raising medical students awareness toward asepsis. Society for Simulation in Healthcare. 2011; 6(2): 65-70. PMid:21487344http://dx.doi.org/10.1097/SIH.0b013e318206953a

[38] Nevo, I., Fitzpatrick, M., Thomas, R. E., Gluck, P. A., Lenchus, J. D., Arheart, K. L., \& Birnbach, D. J. The efficacy of visual cues to improve hand hygiene compliance. Simulation in Healthcare. 2010; 5(6): 325-331. PMid:21330817 http://dx.doi.org/10.1097/SIH.0b013e3181f69482

[39] Shaha, M., Berg, J., Wenzel, J., Shaefer, J., Terhaar, M., Klimmek, R., et al. Excellence in teaching and learning: Students' perspective. Journal of Nursing Education and Practice. 2013; 3(12): 35. http://dx.doi.org/10.5430/jnep.v3n12p35

[40] Henriksen, K., \& Patterson, M. D. Simulation in health care: setting realistic expectations. Journal of Patient Safety. 2007; 3(3): 127-134.

[41] Boulet, J. R., Jeffries, P. R., Hatala, R. A., Korndorffer Jr, J. R., Feinstein, D. M., \& Roche, J. P. Research regarding methods of assessing learning outcomes. Simulation in Healthcare. 2011; 6(7): S48-S51. PMid:21705967 http://dx.doi.org/10.1097/SIH.0b013e31822237d0

[42] Megel, M. E., Bailey, C., Schnell, A., Whiteaker, D., \& Vogel, A. High-Fidelity Simulation: How Are We Using the Videos? Clinical Simulation in Nursing. 2012; 9(8): e305-e310. http://dx.doi.org/10.1016/j.ecns.2012.04.003

[43] Boscart, V. M., McGilton, K. S., Levchenko, A., Hufton, G., Holliday, P., \& Fernie, G. R. Acceptability of a wearable hand hygiene device with monitoring capabilities. Journal of Hospital Infection. 2008; 70(3): 216-222. PMid:18799234 http://dx.doi.org/10.1016/j.jhin.2008.07.008

[44] Gaba, D. M. The future vision of simulation in health care. Quality and Safety in Health Care. 2004; 13(1): i2-i10. PMCid:PMC1765792 http://dx.doi.org/10.1136/qshc.2004.009878

[45] Kardong-Edgren, S., Adamson, K. A., \& Fitzgerald, C. A review of currently published evaluation instruments for human patient simulation. Clinical Simulation in Nursing. 2010; 6(1): e25-e35. http://dx.doi.org/10.1016/j.ecns.2009.08.004

[46] Schmidt, E., Goldhaber-Fiebert, S. N., Ho, L. A., \& McDonald, K. M. Simulation Exercises as a Patient Safety StrategyA Systematic Review. Annals of internal medicine. 2013; 158(5_Part_2), 426-432. PMid:23460100 http://dx.doi.org/10.7326/0003-4819-158-5-201303051-00010

[47] Gates, M. G., Beth Parr, M., \& Hughen, J. E. Enhancing nursing knowledge using high-fidelity simulation. Journal of Nursing Education. 2012; 51(1): 9. PMid:22085206 http://dx.doi.org/10.3928/01484834-20111116-01

[48] Butler, K. W., Veltre, D. E., \& Brady, D. Implementation of active learning pedagogy comparing low-fidelity simulation versus high-fidelity simulation in pediatric nursing education. Clinical Simulation in Nursing. 2009; 5(4): e129-e136. http://dx.doi.org/10.1016/j.ecns.2009.03.118

[49] Kameg, K., Howard, V. M., Clochesy, J., Mitchell, A. M., \& Suresky, J. M. The impact of high fidelity human simulation on self-efficacy of communication skills. Issues in mental health nursing. 2010; 31(5): 315-323. PMid:20394477 http://dx.doi.org/10.3109/01612840903420331

[50] Cooper, S., Cant, R., Porter, J., Bogossian, F., McKenna, L., Brady, S., \& Fox Young, S. Simulation based learning in midwifery education: a systematic review. Women and Birth. 2012; 25(2): 64-78. PMid:21489894 http://dx.doi.org/10.1016/j.wombi.2011.03.004 